\title{
Implementing wiki software for supplementing online learning
}

\author{
Sheung On Choy and Kwok Chi Ng \\ The Open University of Hong Kong
}

\begin{abstract}
This paper reports on a study which investigates the implementation of a wiki system as an additional tool to support student learning in an IT related course offered by the Open University of Hong Kong (OUHK). It focuses on a set of interview data related to the tutors' and students' views on and experience of their use or otherwise of the system in the course. The key results on the tutors' and students' participation in the wiki and factors which facilitated or hindered their use of the system are discussed. The findings indicate that the extent of training provision, the wiki pedagogy and participants' readiness for and awareness of their roles in a collaborative online learning environment are major factors affecting the effective use of the wiki. The add on nature of the wiki in this study also caused workload and motivation problems for the participants. Based on the results, strategies are suggested for implementing wiki based learning in both the OUHK and the wider academic context.
\end{abstract}

\section{Introduction}

Recent rapid advances in wiki technologies have made their application in education more popular. As a web publishing tool which allows users to change content that has already been published, the efficacy of wikis is self evident. The capacity to create, edit and restructure web based content allows students to represent data in a freer manner than existing asynchronous learning tools such as discussion boards. The wiki technologies have expanded the opportunities for distance educators, but also bring new challenges to the process of teaching and learning.

This paper reports on a study in which a wiki was implemented as a supplementary system to support student learning in a distance learning course. The implementation of the wiki was not an entirely successful experience in the study as the participation rate of the students and tutors was low. Follow up interviews were conducted to increase our understanding of issues related to the use and non-use of the system and effective strategies for implementing wiki based learning. 


\section{What are wikis?}

According to Leuf and Cunningham (2001), inventors of the original wiki concept, 'a Wiki is a freely expandable collection of interlinked webpages, a hypertext system for storing and modifying information - a database, where each page is easily edited by any user with a forms-capable Web browser client' (p. 14).

A primary goal for many wikis is to encourage many authors to participate. Wiki access is flexible - all that is needed is a computer with a browser and Internet connection, and no special software is required. Everyone can contribute by adding, changing or commenting on the content. Most importantly, the community of users provides quality control that keeps the content 'on topic'.

Ebersbach et al. (2006) note that the following basic features are common in wikis:

- Editing. Most of the wikis use the same basic page editing functions such as text editing and image, table, list, hyperlink and file insertion.

- Links. Each article can be linked to other articles, and thus form a new network structure.

- History. A function which saves all previous versions or modifications of any single page. It allows tracking of the editing processes of an article since all changes have been documented.

- Recent Changes. This feature can provide a current overview of a certain number of recent changes to wiki pages or all changes within a predefined time period.

- Search functions. Most wikis also offer a classic full text or title search for wiki pages.

Wikis have been considered as one of a number of new and powerful forms of 'social software' capable of supporting a range of collaborative learning activities. The combination of the educational agenda which highlights the social dimensions of learning and the technological affordances of wikis offers insights for transformational shifts in educational practice. The relationship between social software and learning is outlined below.

\section{Social software and learning}

In the educational arena, there is a growing emphasis on the need to support learners not only to acquire knowledge and information, but also 
to develop the resources and skills necessary to engage with social and technical change for lifelong learning (Owen, Grant, Sayers \& Facer, 2006). There are also changes in our understanding of practices of creativity and innovation - from the idea of the isolated individual to the concept of 'communities of practice', where reflection and feedback are important collaborative processes.

Community of practice theories perceive learning as an inherently social activity, situated in a social and cultural context (Wenger, 1998; 2000). Any learning situation, then, has to negotiate both an individual's unique experience and the knowledge of the group. Such a perspective also relates the views of constructivism and collaborative learning. A community can provide the social interaction and relationships which are essential for learners to collaboratively construct social shared knowledge (Palloff \& Pratt, 2005).

It is in the light of these educational trends that educators are interested in the emerging practices in social software. The notion of 'social software' - a phase attributed to Shirky (2003) - is a genre of online services that aims to facilitate interaction through explicit or implicit exchange of social information such as identity, participation, attitude and relationship. They satisfy a broad range of social needs such as presence, notification and shared space. Prime examples of social software include blogs and wikis (Bryant, 2006). Boyd (2003) suggests three defining characteristics of social software:

- Support for conversational interaction between individuals or groups ranging from real-time instant messaging to asynchronous collaborative teamwork spaces.

- Support for social feedback which allows a group to rate the contributions of others.

- Support for social networks to explicitly create and manage a digital expression of people's personal relationships, and to help them build new relationships.

The practices of participating in wikis, and social software more generally, could potentially provide a structure supporting a community of practice model of learning (Grant 2006). Individuals come together and develop a repertoire of shared practices, bringing new experiences to the group and learning from the group's existing practices. The wiki itself can be seen as both the site of participation and the artefact that acts as a record of that community's practices. 


\section{Factors affecting the effective use of wikis in education}

The literature has indicated that wiki technologies have the potential to create online environments which support social activities and interactions, and to promote collaborative learning activities (e.g. Augar, Raitman. \& Zhou., 2004; Williams \& Jacobs, 2004); and they are particularly relevant to the distance education mode (Schwartz, Clark, Cossarin \& Rudolph, 2004). However, the empirical research literature on this subject is rather limited; and in many cases teachers have found the use of wikis in educational contexts to be unsuccessful, or at least not meeting design expectations (Beldarrain, 2006; Davies, 2004). Several issues regarding the effective use of wikis in education are worth noting.

- Critical mass of users. Wiki software allows people to easily add content on the web, with the important addition that it is then editable by other readers. The idea of wiki applications is that the knowledge of the group is greater than that of an individual, and that the group which uses it is also the group which creates it. Therefore, a critical mass of users is very important for the operation of wiki systems. Taking the 'tagging' feature in wikis as an example, the scale and activity level of the user base is critical to systems of social tagging (Richardson, 2006). There must be enough people tagging things in order for any individual to be able to find someone who also tags in a similar way.

- Pedagogical considerations. Wiki pedagogy can also be a significant factor affecting the quality of wiki applications. Bower, Woo, Roberts and Watters (2006) investigated the deployment of two different wikis in two Master's degrees in IT subjects offered by Macquarie University, Australia. Two types of learning task designs were used, weekly whole class extension question tasks, and semester long group projects. Based on the results of the student survey, students completing the former tasks were more opposed to using the wiki than those undertaking the group projects - an authentic activity through the wiki. The authors consider that task authenticity is one of the key factors affecting student contributions and enabling a more favourable wiki learning experience.

- Role of the instructor. The use of wikis in education is related to the collaborative approach to learning. Such an approach requires the transformation of the role of teachers from authoritative instructors into mediated facilitators (Palloff \& Pratt, 2005). The use of wikis in relation to collaborative learning in online courses depends on factors such as the effectiveness of the instructor in promoting group collaboration, the instructor's role in creating the course conditions and climate for establishing an online community, and the instructor's ability to engage students to be active participants and favour student led activities. 


\section{Context of the study}

\section{The OLE system at the OUHK}

As a distance learning institution, the Open University of Hong Kong (OUHK) is very interested in exploring strategies to support student learning through technologies and a combination of various media. OUHK has developed its own learning management system, known internally as the 'Online Learning Environment' (OLE). The components of the OLE include discussion board, web based email, and an electronic assignment handling system.

The OLE provides students with a flexible way to obtain course materials. Apart from traditional, print based course materials and textbooks, the university staff use the OLE to replace surface mail to deliver assignment files, supplementary study materials, and other correspondence with students. Discussion board provide students with a convenient place to ask questions and receive answers from the teaching staff. The electronic assignment handling system administers student assignments. Assignments, which are marked up and commented on, are considered an important element in the distance learning process. The assignment handling system enables students to submit assignments electronically, apply for an extension, inquire about the status of their submitted assignments, and receive timely feedback on assignments from the teaching staff.

The key players in the OUHK education process are students, tutors, and academic staff. Students normally spend much of their time studying alone. To complement the distance learning process, face to face sessions are provided, including tutorial and day school. Part time tutors conduct the face to face sessions. Students in a course are required to submit homework assignments to their tutors (usually four to five times during the course). Tutors then mark the assignments and provide feedback to students.

Every course at the OUHK has an academic staff member as the course coordinator. The coordinator's major responsibility is to supervise the teaching and learning process for that course. This includes making assignments and scheduling examinations, delivering the course materials and supplementary teaching notes, and monitoring students' learning progress, tutors' teaching performance, and the assignment-marking process. 


\section{Implementing a wiki in MT368 as a pilot}

MT368 Networks and Distributed Systems is a higher level course which aims at developing students' knowledge and understanding of the principles and practices underlying the design of networks and distributed systems. For the April 2005 presentation, there were about 100 students enrolled in the course who were divided into three tutorial groups. Each group was taken care of by a tutor who was part time staff member of the institution.

The provision of the wiki system was a supplement to the OLE and was mainly for enrichment purposes. Students' use of the wiki was optional and their participation was completely voluntary. The course coordinator (CC) took the initiative to implement the wiki for the tutors and students, and acted as the system administrator.

The main reason behind such an appropach in the pilot is that the course MT368 is an already well-operated distance learning course with the OUHK's standard online support, the OLE. It would involve many works and policy issues if we advocated using the wiki to act as the major online learning support and requiring students to switch from the OLE to the wiki. Even having such a constraint, we are still interested to study the perception of students towards educational use of wikis, and explore the expected uses and actual uses of the wiki as a supplementary online learning tool.

The selection of the wiki software

Of the many wiki software packages available, Wikka Wakka Wiki 1.1.6.0 (http://wikka.jsnx.com/) was selected for use in the course. This software has some desirable features - for example, supporting user authentication, access control (right on read/write/comment on each page), user pages, and easy tracking of user activities and user-created contents. These features are important because they can protect the MT368 members by allowing them to take ownership of their wikis without public interference. Also, they allow the system administrator (i.e. the CC) to track user activities and user created contents.

Introducing the wiki in addition to the OLE

The selected wiki had some educational benefits which were not available in the OLE. First, it can empower online and team teaching because it provides an easy and non-technical way for the teaching team to continually update the course learning web by instantaneously publishing its constituent resources. The students can then navigate the wiki space and retrieve information easily through the 'Recent Change' function.

Also, students are allowed to contribute in authoring, updating and organising the content in an easy and quick way. They can author or co- 
author new wiki pages that are related to the course content; and they can ask questions, receive feedback and interact with one another through the 'Commenting Section' of each wiki page. Thus, they can have a greater ownership of their learning in the wiki system.

Finally, the CC can use the wiki as an authoring environment to quickly add course information such as course outlines, reference lists and the course schedule. The CC can also utilise various navigation and search features of the wiki to monitor student discussions and their learning processes.

Implementation procedures

A one hour briefing session was conducted at the outset of the semester. The technical features of the wiki system were introduced to the tutors and students, and the rationale for introducing the system was explained. The provision of training was fairly limited as it was assumed that participants would possess a relatively high degree of IT competence, and would not require much technical support to develop proficiency in using the wiki.

To encourage the students to use the wiki more frequently, the following measures were taken:

- The CC used it regularly to announce course news, upload course assignments, and suggest study materials to students;

- The tutors were asked to post tutorial notes and presentation slides after the face to face teaching sessions, to facilitate further discussion on the presented topics after class; and

- The tutors were also encouraged to use the wiki to answer student queries and discuss study matters with them.

\section{Methodology}

\section{Purpose of the present study}

The main issues addressed in the study are: 'How far does the wiki application affect the teaching and learning experiences of the tutors and students in the course concerned?' and 'What factors can facilitate or hinder effective implementation of the wiki system as perceived by the tutors and students?' Specifically, the following issues were examined:

1. How did the tutors and students participate in the wiki application?

2. How did the tutors and students compare their experience in using the OLE and the wiki systems for teaching and learning?

3. Have they encountered any problems in using the wiki system and can the problems be resolved? 
4. How did the tutors and students perceive their roles in online teaching and learning? Did they consider themselves to have performed their roles effectively in the new online learning environment?

5. What principles can be suggested for effective implementation strategies of wikis in distance education?

\section{Data collection method}

An invitation for interview and the interview schedule were sent to the tutors and students in June 2005. Three tutors and five students participated in the interviews.

Table 1: The interview schedule for tutors and students

The interview schedule for tutors

1. How have you used the wiki system for teaching? Which components did you use most often? Why?

2. How would you compare your experience in managing the OLE and the wiki systems?

3. Have you encountered any problems when using the wiki? If so, what were they? How did you try to solve them?

4. How do you perceive your teaching role in the online learning environment in general and in wiki in particular?

5. What are your expectations of students' roles in the wiki? To what extent do you consider that they have performed their roles effectively so far?

6. Do you have you any suggestions for improving the use of wiki in the future? For example, are there any additional features which you consider should be included in the wiki system?

The interview schedule for students

1, In what ways have you participated in the wiki system so far? Please give some examples?

2. In comparison with the OLE, what was good/bad about using the wiki?

3. Have you encountered any problems when participating in the wiki? If so, what were they? How did you try to solve them?

4. What are your expectations of the tutor's role in the wiki? To what extent do you consider that your tutor performed his/her role effectively?

5. How would you describe the ways in which you interact with your tutor and the students in the wiki system?

6. Do you have you any suggestions for improving the use of wiki in the future? For example, are there any additional features which you consider should be included in the wiki system?

The interviews adopted a semi-structured approach (see Table 1) and a Research Assistant helped to conduct them by phone. They were carried out in Cantonese, and were transcribed and translated into English for analysis. 


\section{Interview data analysis}

Three tutors (labelled T1 to T3 in the quotations in the results section) and five students ( 1 to $\mathrm{S} 5$ ) participated in the interviews during the period from October to November 2005.

The tutor and student interview data sets were first handled separately. Interviewees' responses to similar questions were grouped so that common responses with respect to similar questions were sorted. Once the data had been ordered, it was possible to identify themes that emerged from the data. The themes that emerged from both the students' and tutors' data sets were then compared for triangulation purposes, and were discussed by the authors for conceptual verification. Finally, the coded data were crosschecked by the authors to ensure the validity and reliability of data interpretation.

\section{Results}

\section{Participation in the wiki}

The tutors' participation

All the tutors had used the wiki to post and update teaching notes and materials for students. They considered this practice was very useful as the teaching notes can be shared among different groups of students and tutors. Also, they found the wiki platform benefited communication between the tutors and the CC. Such views are illustrated by the comment:

T1: I also log in to wiki as we need to update our course materials. We will take a look at how other tutors have updated their materials ... One more thing for using wiki, we need to report the attendees at each tutorial in wiki for the CC for compiling a summary figure of attendance. Wiki is really a platform for communication between the $\mathrm{CC}$ and the tutors.

The students' participation

However, the tutors noted that the students rarely used the wiki to communicate with them and their fellow students. Students accessed the wiki mainly for downloading tutors' notes. Two students (S1, S2) noted that they had tried to create new topics and/or add comments to respond to other topics. However, their purposes were to get themselves familiar with the wiki features rather than having a need for any discussion.

\section{Strong features of the wiki (in comparison with the OLE)}

When asked to compare their experience in using the OLE and wiki system, some strong features of wiki technologies in supporting teaching and learning were commented upon by the tutors and students. 
Retrieving latest messages/changes more easily (the Recent Change feature)

Some tutors considered that it was very convenient to check the latest information in the wiki system. As noted by a tutor (T2), 'whenever I log in, I will click the link [Recent Change] to see if there is any new message ... When there are lots of postings in the OLE, there will be many threads and I have found it very difficult to find the latest postings.'

One student also made a similar comment:

S1: I am not very familiar with wiki. Therefore, I don't see any big difference between wiki and OLE. The only difference that I found is that there is better structure in wiki than OLE. In wiki, all the information I need is already in the host page.

Greater flexibility in supporting multimedia functions and design of homepages One tutor noted that the capacity of wikis to support multimedia functions and content organisation structures benefited his teaching. 'A good thing about the wiki is that it can support more media such as Flash, for example, putting a PowerPoint file into Flash with flow charts... Also, I can have more control over the design of the webpage. On the contrary, there are more restrictions when using the OLE (in designing my own page).' (T2)

Two students also considered the above features benefited their learning, as is illustrated by the following comments:

S2: It can add graphics/ pictures without the need to make an attachment. Although it may need another server to store the graphics and add a link to wiki, it is still easier to see/read.

S3: A good point about wiki - I can see tutor's PowerPoints in the wiki interface and there's no need to download.

Greater potential for facilitating collaboration work

Despite the fact that the tutors and students were not exposed to any collaborative learning experience in the wiki, some of them were aware of the potential of the system for facilitating collaborative tasks. For example, one tutor noted that 'The wiki has a component for collaboration; we can add things to our homepages or even add on each other's (homepages)' (T3). Also, two students noted that the wiki structure allows the adding of comments under a specific topic, which 'can support a group of people to develop and explore a topic collaboratively' (S2) and 'such a feature is better than the OLE' (S4).

\section{Problems in using the wiki system}

When asked whether they had encountered problems when participating in the wiki, several issues emerged - which can perhaps explain the low wiki participation rate in this study. 
Technical issues (not familiar with the wiki)

Despite the fact that this was a group of participants who possessed a relatively high level of IT competence, they encountered technical problems which hindered them from using the system more extensively. A tutor who noted that one needs to acquire certain skills for using some basic features in the wiki made the following comment:

T2: Wiki is bit difficult to use at the beginning. You need to have some knowledge of HTML (formatting rules). It is not that simple to create some effects such as creating a table or opening a new thread in wiki ... I didn't know how to type the code into the wiki system at the beginning - for example, create a page with a file for people to download - and I had to refer to the help menu. It is a very comprehensive menu, but I didn't have time to go through it all.

Two students indicated clearly that technical issues had hindered their use of the wiki, as illustrated by the following comments:

S2: There are students like me who are new to wikis. We need time to explore the wiki system. If you want to start a new topic, but just don't know how to do it ... you have to go back to the help menu to refresh your memory on how to use wiki. Because I don't post messages to wiki very often, I almost need to go to the help menu every time.

S4: I haven't got used to the wiki's interface. Its structure seems a bit complicated. I sometimes get lost (don't know where I am).

One course two systems - working habits and extra workload problems In comparing their OLE and wiki experience, the challenges of implementing the wiki as an add-on stood out. The tutors highlighted the following problems:

T1: Students rarely communicate in the wiki. I guess it is because students have got used to the OLE. Only MT368 has set up this [wiki] platform and this gives extra work to students ... It's hard to motivate them to change the platform. (Motivation problems)

T2: My students don't use the wiki very often. They usually use the OLE as these students have used it for a long time. They said they preferred to use the OLE. It is much more convenient for students as they can see all of their courses in OLE. (Working habits)

T3: I think it is quite difficult to make students change (from the OLE) to use this platform. All other courses use the OLE and students can view all the courses they are enrolled in with one single login. To use the wiki, students have to $\log$ in to another platform. It is quite inconvenient for them ... (Causing inconvenience)

In the following comments, three students explained why they preferred using the OLE. 
S3: I personally prefer to have all discussion in one platform. Now, there is discussion in both the OLE and wiki. Sometimes, it's inconvenient to look up information from two different platforms. (Causing inconvenience)

S4: I personally believe that unifying the interface across all subjects would be better. I found the wiki is not necessary at this point unless there is something which can only be offered by it and not by the OLE. If it is simply provides us with another platform for discussion and asking questions, I believe these functions should remain in the OLE. (Uniqueness of the wiki system)

S5: Because all other subjects use the OLE, I have got used to logging in to the OLE first. Logging in to the wiki becomes extra work for me. Also, I know how to use the OLE already and not many students use the wiki. Many of them post their discussion in the OLE. Wiki takes us some time to learn how to use. (Workload implications)

\section{Pedagogical issues}

Issues related to wiki pedagogy were also highlighted by a tutor and a student.

T3: Although wiki can engage students in collaborative work, this course does not require any collaborative work. If wiki is used in a business company which requires a group of people to develop something, I believe people can benefit from it. But this course does not maximise such a strength.

S2: So far, I haven't seen anyone starting a new topic and starting to develop it collaboratively... I guess it's because we are all part-time students and we don't have a special topic (which needs to be discussed in the wiki).

\section{The tutors' roles in online teaching}

The tutors were asked how they perceived their teaching roles in online learning in general and in the wiki in particular and they expressed the following views:

Adviser/helper

Two tutors (T1 and T3) considered that their major roles in online teaching were to answer students' questions/enquiries and help them to clarify course concepts. T1saw his main duties in the OLE and wiki as 'checking whether there is any new email, responding to students' questions; and replying in the discussion forum' (T1) but he noted that students did not prefer posting messages in the wiki.

T3 considered that his major role was to offer help/advice to students for their learning. 'Whenever students have problems in an assignment, I will try to offer help such as clarification and provide resources to help students understand more about the concepts.' However, T3 also noted that adult 
learners' learning characteristics needed to be addressed. 'As many of them are adults, it is impossible to teach them like kids ... When they raise a question, I try not to give them an answer. Instead, I will prompt them by asking how they would address the question. I try to give them guidelines and lead them to reach the answer by themselves.' His comment appears to suggest that adult learners should take a more self directed role in learning, but he didn't explain further how this could be implemented in online learning.

\section{Facilitator}

T2 considered his major role in online teaching was to facilitate students to initiate and lead discussion. 'I believe that the most important thing is to facilitate students to begin conversation ... If the discussion atmosphere is not established, they will put even fewer postings and a vicious cycle will be created.' In his comments, the issue of students' learning roles was raised again. T2 observed that 'students do not like to discuss very much and seem passive in learning' which can make online teaching more difficult.

Students' expectations about tutors' roles

Students were asked about their expectations of the tutors' role in the wiki. Their responses can triangulate the tutors' comments above.

S2 and S4 responded to the question in a very straightforward manner the tutors' role was to answer their learning queries. S1 and S5 also mentioned this point, but they elaborated their views further. S1 considered that it was important for tutors to provide them with relevant resources to help their learning, while S5 expected his tutor to 'raise some questions or guide students to initiate discussion' in the online forum. However, S5 observed that this could be a difficult task for the tutors if there was not a critical mass in the forum.

S5: I can see they replied to some students' questions which were posted in the wiki. However, as there are fewer and fewer students posting messages there, the need to reply becomes less. (Critical mass)

\section{The students' roles in online learning}

The tutors' perspectives

Clearly, students also play a significant role in online learning. As T2 noted above, his students seemed passive in discussion and he observed that there were only five to six students who were more active in his group. T3 wished his students would 'not just raise questions and create home pages for self introduction, but also take part in discussion', and he commented that the potential of the wiki in supporting collaboration had not been utilised in their studies. T1 wished students 'could be more active in 
participating in the wiki' but he understood that logging in to two systems placed an extra workload on students.

The students' feedback

The students were not asked directly about their role in online learning. Rather, they were asked to describe the ways in which they interact with their tutors and students in the wiki.

Not surprisingly, not many comments were made by students on this topic as their involvement in the wiki was very limited. However, all five students involved indicated that they had posted questions and were satisfied with the interaction opportunities provided by the OLE. In one of the students' comments, the issue of critical mass of users in the wiki was raised again.

S1: I participate a lot in OLE discussion. I read messages every day. If I have question, I will also post and ask. Because I am not familiar with wiki, I post messages less there ... Another issue is that very few people post messages in wiki and I couldn't find any very important information. Classmates usually discuss assignments in the OLE. It may be only my impression. Also, I personally find this course is quite "quiet". There may be no new postings for 3 or 4 days. Therefore, there are not many new things. (Critical mass)

\section{Further improvements}

Finally, the tutors and students were asked to make recommendations for improving the use of wikis in the future and the following comments were made:

\section{Pedagogical considerations - collaborative tasks}

T3: If there are projects that can have tutors and students develop collaboratively, I would think the collaborative aspects of wiki could be maximised ... I would suggest designing some mini projects in which students and tutors work together. This course should be able to design some projects with a collaborative component.

\section{Unifying the learning platform}

T1: If I really have to, I would suggest having all courses use the same platform.

S3: All courses in one platform. If discussions on this course are all in wiki exclusively, I will check the wiki discussion board ... I personally find wiki is a good interface.

S4: As I mentioned earlier, if wiki can provide functions that do not duplicate the OLE and the course really needs this platform, it would be much better. 
S5: When both OLE and wiki are available for students and the OLE is used for all other courses, it would be very hard to motivate students to use the wiki.

Making the Wiki more user friendly

T2: Wiki is overloaded with text.

T3: Except for the first page, wiki is loaded with text. There is still room to improve this aspect of wiki.

S5: Provide detail notes or briefing to introduce how to use wiki.

\section{Concluding remarks}

This paper reports on a pilot study in which a wiki was used as an innovation to supplement online learning. The potential educational benefits of wikis have not been fully exploited because of limited participation. However, several implications for implementing more effective wiki based learning can be drawn from the interview data.

First, the technical challenges of using wikis as new learning tools should not be overlooked. Although the participants in this study had an IT background and some initial training was provided, some students indicated that they were not technically proficient in using the wiki and required more guidance and support. Some tutors also noted that it took time for them to become familiar with the system. Allowing more time for participants to become proficient users of the system and strengthening the provision of technical guidance and support can improve participants' experience.

The participants did not seem very clear about the functional affordance of the tool for promoting the social dimension of learning. The interview data appear to suggest that most of the students and tutors saw the wiki as a tool for communication or course administration. Also, the data seem to suggest that the tutors and students considered the wiki mainly as a platform for questioning and answering. Such a perception of their roles would make it difficult to implement a collaborative approach to learning. Explicitly drawing students' attention to the ways in which collaborating via wikis may improve their motivation, and thus the quality and quantity of their contributions. Clear expectations about tutors' roles should also be spelled out. Practices may change over time as students and teachers become more familiar with the affordances of the wiki as a learning tool.

Of course, the design of learning tasks obviously affects students' motivation to participate and their learning experience. For example, Bower et al. (2006) note that wikis are suited to tasks requiring negotiated meaning, and task authenticity can have an impact on student 
contributions. Integrating short term or small scale group projects or problem based tasks can be a promising way to explore and utilise the pedagogical potential of the wiki applications. To optimise the effectiveness of the learning experience, academics should anticipate the collaborative requirements of the tasks being prescribed, and then make every effort to ensure that the tools provided meet those requirements.

As a follow up to the present study, another study is planned and will be conducted in the next presentation of the same course. The planned study will involve collaborative writing tasks and peer review activities. More specifically, the whole class of students will be divided into teams of three or four students. Each team is then ask to collaboratively author an article on a specific and common topic. For example, in the context of the course MT368, the tentative topic is 'web services'. Each team is required to write an article on what are web services, what is 'service oriented architecture', web services in action, programming demonstration on web services, and resources and references on web services. After the authoring stage, every write ups will be open for peer review. Students are encouraged to use the commenting area of each wiki page to give their comments. To ensure the participation rate and motivate students, the two stages of the activities will be taken as a part of the continuous assessment. To increase the students' familiarity with the wiki, a briefing session and a training session will be conducted at the beginning of the course. To further increase students' proficiency in using the wiki, an icebreaker exercise as briefed in Augar et al. (2004) will be conducted well before the collaborative writing task starts. We shall report on our follow up study in the near future.

The implementation of the wiki as an add-on involves workload and motivation problems for the participants. There are pros and cons in adopting a unified approach for online course delivery (i.e. the OLE system at the OUHK). A well-developed system provides templates for creating courses and a range of functionality, but the pedagogical orientation of a unified software package may not be desirable for all courses - for example, the OLE system may not be desirable if a constructivist approach is adopted. The University should therefore evaluate the effectiveness of the courseware periodically. It should also develop strategies to encourage individual pilot studies using other software or alternative approaches to online teaching. This can be a useful way of gaining experience and providing momentum for innovation.

In conclusion, wikis, and social software more generally, have the potential to support and structure communities where individuals come together to share, learn, create and collaborate with each other. It can also be a useful tool in the shared repertoire of communities of practice engaged in collaborative learning. However, issues such as technical training and 
support, appropriate pedagogical design and the participants' roles in the collaborative work that needs to accompany the use of the software, must be considered carefully. This study has highlighted some important issues regarding the use of wikis in distance education, but there is clearly a need for further research in this area.

\section{Acknowledgement}

This research was supported by School funds from the Open University of Hong Kong. We would like to thank Eunice Yim for collecting and transcribing the data.

\section{References}

Augar, N., Raitman, R. \& Zhou, W. (2004). Teaching and learning online with wikis. In R. Atkinson, C. McBeath, D. Jonas-Dwyer \& R. Phillips (Eds), Beyond the comfort zone: Proceedings of the 21st ASCILITE Conference (pp.95-104). Perth, 5-8 December. http: / / www.ascilite.org.au/conferences/ perth04/procs/augar.html

Beldarrain, Y. (2006). Distance education trends: Integrating new technologies to foster student interaction and collaboration. Distance Education, 27(2), 139-153.

Bower, M., Woo, K., Roberts, M. \& Watters, P. (2006). Wiki pedagogy: A tale of two wikis. The International Conference on Information Technology Based Higher Education and Training (ITHET). University of Technology, Sydney, Australia, 1013 July.

Boyd, S. (2003). Are you ready for social software? [viewed 15 Sep 2006] http: / / www.darwinmag.com/ read/050103/ social.html

Bryant, T. (2006). Social software in academia. Educause Quarterly, 29(2).[viewed 4 Apr 2007] http: / / www.educause.edu/apps/eq/eqm06/eqm0627.asp

Davies, J. (2004). Wiki brainstorming and problems with wiki-based collaboration. [viewed 15 Sep 2006] http:/ / www-users.cs.york.ac.uk/ kimble/teaching/ students / Jonathan_Davies/Jonathan_Davies.html

Ebersbach, A., Glaser, M. \& Heigl, R. (2006). Wiki: Web collaboration. Berlin Heidelberg: Springer-Verlag.

Grant, L. (2006). Using wikis in schools: A case study.[viewed 15 Sep 2006]. http: / / www.futurelab.org.uk/ research/discuss / 05discuss01.htm

Leuf, B. \& Cunningham, W. (2001). The wiki way: Quick collaboration on the web. Boston: Addison-Wesley.

Owen, M., Grant, L., Sayers, S. \& Facer, K. (2006). Social software and learning: An Opening Education report from Futurelab.[viewed 15 Sep 2006]

http:// www.futurelab.org.uk/research/opening_education/social_software_01.htm 
Palloff, R. M. \& Pratt, K. (2005). Collaborating online: Learning together in community. San Francisco: Jossey-Bass.

Richardson, W. (2006). Blogs, wikis, procasts, and other powerful web tools for classrooms. Thousand Oaks: Corwin Press.

Schwartz, L., Clark, S., Cossarin, M. and Rudolph, J. (2004). Educational wikis: features and selection criteria. International Review of Research in Open and Distance Learning, 5(1). [viewed 15 Sep 2006].

http: / / www.irrodl.org/index.php/irrodl/article/view/163/244

Shirky, C. (2003). A group is its own worst enemy: A speech at ETech. [viewed 15 Sep 2006] http:/ / www.shirky.com/writings / group_enemy.html

Wenger, E. (1998). Communities of practice: Learning, meaning and identity. Cambridge: Cambridge University Press.

Wenger, E (2000). Communities of practice and social learning systems. Organization $7(2), 225-246$

Williams, J. B. \& Jacobs, J. (2004). Exploring the use of blogs as learning spaces in the higher education sector. Australasian Journal of Educational Technology, 20(2), 232-247. http: / / www.ascilite.org.au/ajet/ajet20/ williams.html

Sheung On Choy, Lecturer, School of Science and Technology

The Open University of Hong Kong, 30 Good Shepherd Street, Ho Man

Tin, Kowloon, Hong Kong. Email: sochoy@ouhk.edu.hk Web: http: / / www.stevenchoy.com/

Kwok Chi Ng, Assistant Professor, School of Education and Languages The Open University of Hong Kong, 30 Good Shepherd Street, Ho Man Tin, Kowloon, Hong Kong. Email: kcng@ouhk.edu.hk 